\title{
Изучение закономерностей осаждения тонких сорбционно-активных пленок диоксида марганца на различных полимерных носителях
}

\author{
(C) 2021 Семенищев В.С., Оглезнева В.Ю., Титова С.М., \\ Малышев А.С., Филинкова В.К. \\ Уральский федеральньй университет, Екатеринбург. \\ Поступила в редакцию 15.01.2021 г.
}

DOI: $10.17308 /$ sorpchrom.2021.21/3471

\begin{abstract}
Диоксид марганца $\left(\mathrm{MnO}_{2}\right)$ используется в качестве сорбционного материала для выделения из водных сред широкого спектра веществ. Известен ряд композиционных материалов, содержащих $\mathrm{MnO}_{2}$, при этом в научной литературе отсутствуют систематические данные о возможностях получения плоских тонкослойных сорбентов диоксида марганца на других полимерных носителях. В работе был синтезирован ряд плоских тонкослойных сорбентов, состоящих из диоксида марганца, нанесенного на поверхность различных носителей. В качестве носителей были использованы наиболее распространенные плоские материалы - полиэтилен (ПЭ), полипропилен (ПП), биаксиально-ориентированная полипропиленовая плёнка (БОПП), полиэтилентерефталат (ПЭТФ), триацетатцеллюлоза (ТАЦ). Пленки выдерживали в кислом растворе перманганата калия, отмывали и определяли содержание марганца. Показано, что по скорости осаждения диоксида марганца на поверхность носителя данные материалы располагаются в ряд: ТАЦ>>ПЭ>БОПП>ПЭТФ диоксида марганца на поверхности полимерных носителей хорошо аппроксимируются прямыми линиями $\left(\mathrm{R}^{2}=0.964-0.997\right)$; по результатам линейной обработки зависимостей были определены скорости

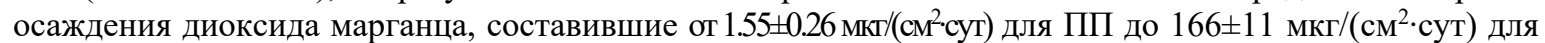
ТАЦ. Показано, что высокая скорость осаждения диоксида марганца на поверхности ТАЦ по сравнению с другими полимерными носителями, наиболее вероятно, обусловлена макропористой текстурой поверхности ТАЦ. Также показано, что при удельном содержании диоксида марганца порядка 150-300 мкг/см², достигаемом за 1-2 суток обработки ТАЦ в растворе перманганата, образуется сплошной равномерный сорбционно-активный слой, а при большем времени выдержки увеличение средней толщины слоя происходило за счет разрастания отдельных кристаллитов уже на поверхности сплошного слоя диоксида марганца, приводя к существенной неоднородности сорбционно-активной поверхности, а также к устойчивой деформации пленки. На серии полученных сорбентов была исследована сорбция ${ }^{223} \mathrm{Ra}$. Показано, что количество фазы диоксида марганца в составе тонкослойных сорбентов практически не влияло на сорбцию радия из бессолевого раствора, однако сильно влияло при сорбции из $0.5 \mathrm{M}$ $\mathrm{NaCl}$. Также для сорбента $\mathrm{MnO}_{2}$-ТАЦ показано ухудшение качества альфа-спектра за счет диффузии радия вглубь сорбента.
\end{abstract}

Ключевые слова: тонкослойные сорбенты, диоксид марганца, осаждение, радий.

\section{Введение}

Диоксид марганца $\left(\mathrm{MnO}_{2}\right)$ используется в качестве сорбционного материала для выделения из водных сред широкого спектра веществ, таких как мышьяк [1,2], кадмий [2], свинец [3] и хром [4], а также радиоизотопы урана $[3,5]$, кобальта [6, 7], стронция [8], свинец [7] и радий [9-10]. Кроме того, описаны такие области применения сорбентов на основе $\mathrm{MnO}_{2}$, как извлечение лития [11] и палладия [12] из промышленных источников и удаление органических соединений [13]. В методах 
сорбционного разделения диоксид марганца может использоваться в чистом виде $[3,5,6]$, однако, как правило, он образует достаточно мелкие осадки, что затрудняет его отделение от водной фазы и делает невозможным его использование при разделении в колоннах. Для устранения этих недостатков был разработан ряд композиционных сорбентов, содержащих $\mathrm{MnO}_{2}$. Среди наиболее распространенных связующих агентов или матриц для диоксида марганца можно выделить $\mathrm{SiO}_{2}$ [14-15], активированный уголь [11], альгинатные материалы [2], метилметакрилат [16], пенополиуретан [17], волокнистые материалы $[18,19]$, ионообменные смолы $[1,4,10]$, а также плоские пленки [20]. Тонкослойные плоские сорбенты на основе диоксида марганца используются в методах определения радия в пробах воды. Основное преимущество этих материалов - возможность прямого измерения изотопов радия в плоском сорбенте с помощью альфа-спектрометрии непосредственно после сорбционного выделения. Известно использование полиамидных дисков и пленок качестве материалов-носителей для тонкослойных сорбентов, содержащих $\mathrm{MnO}_{2}$ [21]. При этом в научной литературе отсутствуют систематические данные о возможностях получения плоских тонкослойных сорбентов диоксида марганца на других полимерных носителях. Целью данной работы было исследование возможности осаждения тонкого слоя диоксида марганца на поверхность различных плоских полимерных носителей.

\section{Экспериментальная часть}

В качестве носителей были взяты наиболее распространенные плоские полимерные материалы - полиэтилен (ПЭ), полипропилен (ПП), биаксиально-ориентированная полипропиленовая плёнка (БОПП), полиэтилентерефталат (ПЭТФ), триацетатцеллюлоза (ТАЦ). Образцы были обезжирены промывкой в 1 М $\mathrm{NaOH}$. В качестве исходного сырья для ТАЦ была взята черно-белая фотопленка.
Фотоэмульсию и желатин с пленки триацетатцеллюлозы отмывали губкой с $2 \mathrm{M}$ раствором $\mathrm{NaOH}$, после чего промывали дистиллированной водой и сушили на воздухе при комнатной температуре. После предварительной подготовки пленки были выдержаны в растворе $\mathrm{KMnO}_{4}$, после чего отмыты дистиллированной водой до полного чезновения розовой окраски в промывном растворе и высушены на воздухе при комнатной температуре. Во всех случаях концентрация $\mathrm{KMnO}_{4}$ составляла 0.1 моль/дм ${ }^{3}$, исходное значение $\mathrm{pH}$ раствора находилось в диапазоне 1.51.7 , при этом после синтеза значение $\mathrm{pH}$ повышалось незначительно, не более 0.1 ед. Для определения содержания диоксида марганца образцы сорбентов известной площади выщелачивали $1 \mathrm{M} \mathrm{HCl}$ в течение 1 недели до полного растворения диоксида марганца, наличие которого контролировали по цвету образца. Концентрацию марганца в полученном растворе определяли на масс-спектрометре NexION 350 (Perkin Elmer, США) без предварительной пробоподготовки. Полученный результат пересчитывали на удельное содержание диоксида марганца $\left(\right.$ мкг/ $\left.\mathrm{cm}^{2}\right)$. Относительная погрешность определения концентрации марганца не превышала 4\%.

Электронные микроизображения получали на растровом электронном микроскопе ThermoScience Scios 2 LoVac (JEOL Ltd., Япония) при ускоряющем напряжении $\mathrm{U}=0.5-1 \mathrm{\kappa B}$ и токе зонда $\mathrm{I}=20$ нА. Оптические микрофотографии модифицированных пленок получали с помощью инвертированного оптического микроскопа Olympus GX-71 (Япония). Регистрацию и документирование наблюдений производили в системе анализа изображений «SIAMS Photolab».

Исследование сорбции радия проводили с использованием ${ }^{223} \mathrm{Ra}$, полученного из изотопного генератора на основе ${ }^{227}$ Ас. Измерения сорбентов после сорбции радия осуществляли на альфа-спектрометре Мультирад-АС (ОOО НПП «Доза», Россия) с полупроводниковым 
Таблица 1. Содержание диоксида марганца на поверхности плоских носителей после экспозиции в растворе перманганата калия

Table 1. The content of manganese dioxide on the surface of flat carriers after exposure in a potassium permanganate solution

\begin{tabular}{|c|c|c|}
\hline Носитель & Тип обработки & 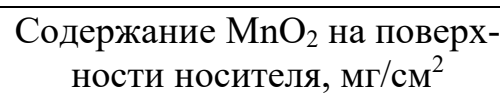 \\
\hline ПЭ & \multirow{5}{*}{ Однократная (1 сутки) } & 12.5 \\
\hline ТАЦ & & 186.2 \\
\hline$\overline{\Pi \Pi}$ & & 3.3 \\
\hline БОПП & & 1.8 \\
\hline ПЭТФ & & 3.8 \\
\hline ПП & \multirow{3}{*}{ Однократная (1 неделя) } & 11.1 \\
\hline ПЭТФ & & 12.2 \\
\hline БОПП & & 18.2 \\
\hline$\Pi \Pi$ & \multirow{3}{*}{ Двукратная (1 сутки+1 неделя) } & 23.7 \\
\hline ПЭТФ & & 13.1 \\
\hline БОПП & & 20.4 \\
\hline
\end{tabular}

поверхностно-барьерным детектором.

\section{Обсуждение результатов}

В таблице 1 приведены результаты определения содержания диоксида марганца на поверхности плоских носителей после однократной экспозиции в растворе перманганата калия в течение 1 суток. По адсорбционной способности по отношению к диоксиду марганца различные плоские носители можно располо-

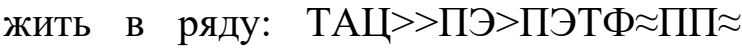
БОПП. В случае ПП, БОПП и ПЭТФ была также протестирована двукратная обработка раствором перманганата калия: образцы после однократной суточной экспозиции извлекали из раствора, промы вали дистиллированной водой, сушили, после чего выдерживали в свежем растворе перманганата калия еще в течение 1 недели (табл. 1). С помощью двукратной обработки удалось добиться значительного большего содержания диоксида марганца на поверхности образцов. Интересно, что двукратная обработка приводила к несколько большей толщине слоя диоксида марганца на поверхности носителей, чем однократная в течение 1 недели, при том, что время выдержки пленок в растворе перманганата калия было практически одинаковым. Скорее всего, это можно объяснить тем, что при первой обработке происходит образование зародышей кристаллов на поверхности пленки, после чего при второй обработке происходит более интенсивный рост фазы диоксида марганца на этих зародышах.

Для определения кинетики роста слоя диоксида марганца на полимерных носителях был приготовлен раствор перманганата калия, в который было помещено по 7 образцов полимерных пленок, предварительно обезжиренных в 1М гидроксиде натрия. Образцы каждой из пленок извлекали из раствора через различные промежутки времени от 1 до 169 часов $(\approx 1$ неделя), после чего их отмывали дистиллированной водой и определяли удельное содержание диоксида марганца. Зависимости роста фазы диоксида марганца на различных полимерных носителях от времени приведены на рис. 1. Из кинетических кривых видно, что при времени осаждения до 1 недели подтверждается практически та же зависимость скорости осаждения диоксида марганца от материала носителя: ТАЦ >> ПЭ > БОПП > ПЭТФ $\approx$ ПП. При этом полученные зависимости достаточно хорошо аппроксимируются прямыми линиями, кроме ТАЦ, для которого наблюдался выход на насыщение после 5 суток осаждения. В таблице 2 представлены результаты линей 

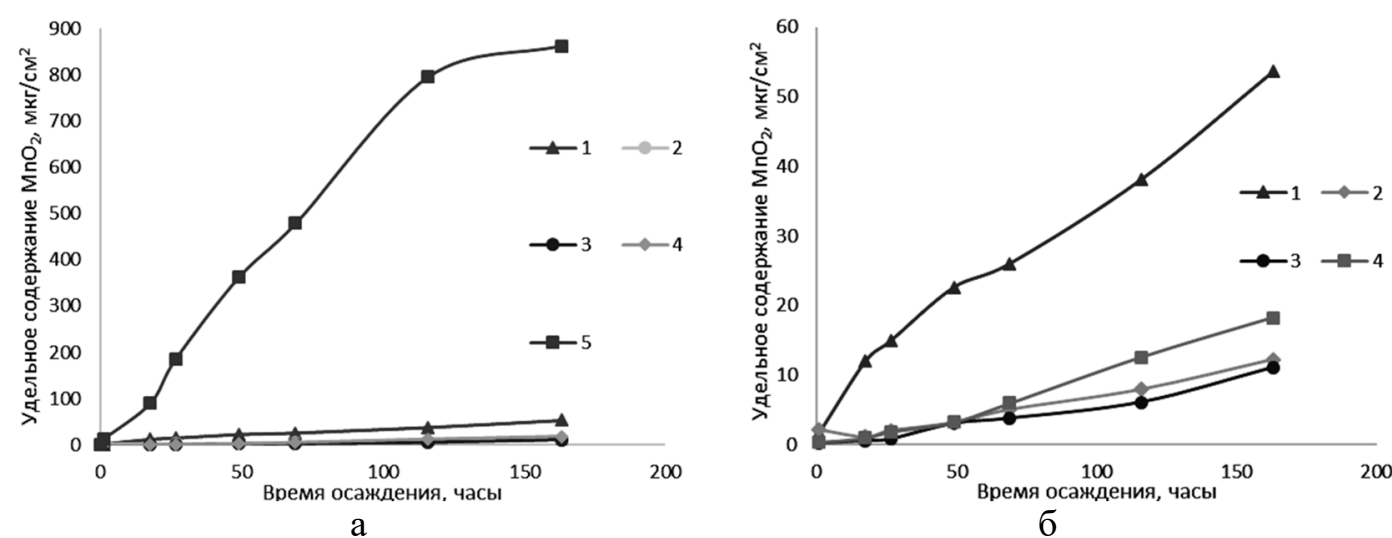

Рис. 1. Зависимости содержания диоксида марганца на поверхности различных полимерных носителей от времени обработки в растворе перманганата калия: а - все пленки,

б - все пленки за исключением ТАЦ. 1 - ПЭ, 2 - ПЭТФ, 3 - ПП, 4 - БОПП, 5 - ТАЦ

Fig. 1. Dependences of the content of manganese dioxide on the surface of various polymer carriers on the time of treatment in a potassium permanganate solution: a) all films, b) all films except CTA. 1 - PE, 2 - PET, 3 - PP, 4 - BOPF, 5 - CTA

Таблица 2. Результаты линейной аппроксимации зависимостей содержания диоксида марганца на поверхности различных полимерных носителей от времени обработки и средние скорости осаждения диоксида марганца.

Table 2. Results of linear approximation of the dependences of the manganese dioxide content on the surface of various polymer carriers on the treatment time and the average deposition rate of manganese dioxide.

\begin{tabular}{|c|c|c|c|c|}
\hline Материал носителя & $\mathrm{a} \pm \Delta \mathrm{a}$ & $\mathrm{b} \pm \Delta \mathrm{b}$ & $\mathrm{R}^{2}$ & $\begin{array}{c}\text { Скорость осаждения } \\
\mathrm{MnO}_{2}, \text { мкг } /\left(\mathrm{cm}^{2} \cdot \text { сут }\right)\end{array}$ \\
\hline ТАЦ & $6.9 \pm 0.5$ & $-0.7 \pm 25$ & 0.997 & $166 \pm 11$ \\
\hline ПЭ & $0.31 \pm 0.05$ & $4.0 \pm 3.8$ & 0.977 & $7.4 \pm 1.1$ \\
\hline ПЭТФ & $0.069 \pm 0.013$ & $0.4 \pm 1.0$ & 0.964 & $1.64 \pm 0.31$ \\
\hline ПП & $0.065 \pm 0.011$ & $-0.4 \pm 0.8$ & 0.973 & $1.55 \pm 0.26$ \\
\hline БОПП & $0.113 \pm 0.015$ & $-0.8 \pm 1.2$ & 0.970 & $2.71 \pm 0.36$ \\
\hline
\end{tabular}

ной аппроксимации полученных зависимостей и рассчитанная средняя скорость осаждения диоксида марганца на поверхность различных полимерных носителей. Интересно, что полученные максимальные значения удельного содержания диоксида марганца на носителях ТАЦ и ПЭ

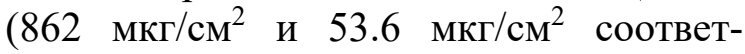
ственно) существенно превышали значения, известные из литературы для этих

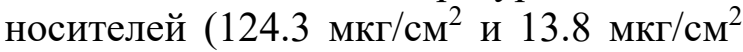
соответственно [22]), а также для поли-

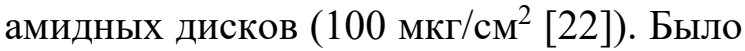
отмечено, что при модифицировании ТАЦ в растворе перманганата калия в течение 2 суток и более визуально наблюдались стойкая деформация пленки и растрескивание поверхности сорбционного слоя.
Столь радикальное отличие в скорости осаждения диоксида марганца на поверхность ТАЦ от осаждения на поверхность других пленок можно объяснить разницей в текстуре поверхности исходных пленок. На рис. 2 представлены электронные микрофотографии образцов исходных пленок ПЭ и ТАЦ. Видно, что поверхность исходной пленки ТАЦ покрыта сетью пор диаметром 50-100 нм, тогда как поверхность ПЭ (а также всех остальных полимерных пленок) имеет достаточно гладкую беспористую текстуру. Наиболее вероятно, что именно поры пленки ТАЦ являются центрами, на которых начинается кристаллизация фазы диоксида марганца, обеспечивающими хорошую адгезию оксидномарганцевого слоя. Предположение о том, что рост слоя диоксида марганца начинается 


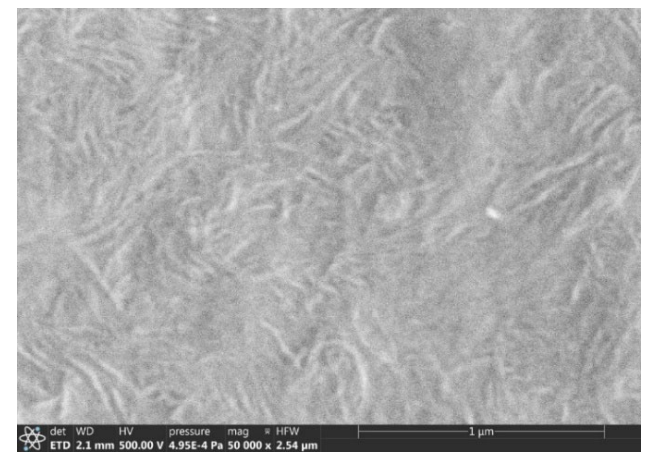

a

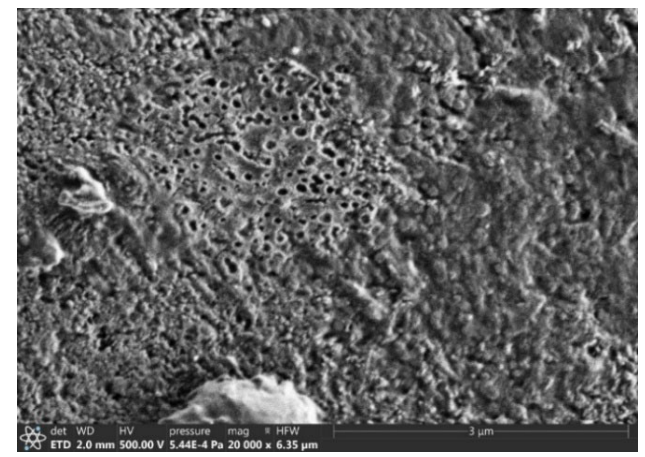

6

Рис. 2. Электронные микроизображения образцов исходных пленок ПЭ (а) и ТАЦ (б) Fig. 2. Electron microimages of samples of initial PE (a) and CTA (b) films.

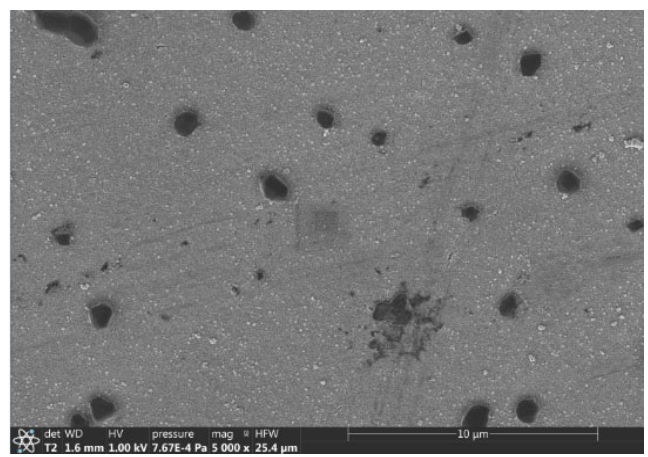

a

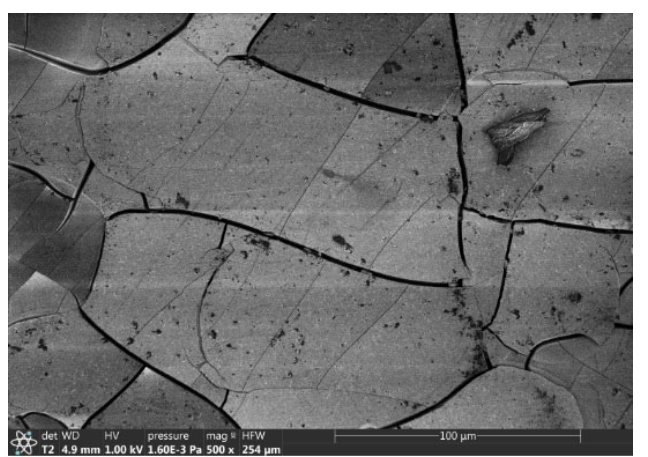

6

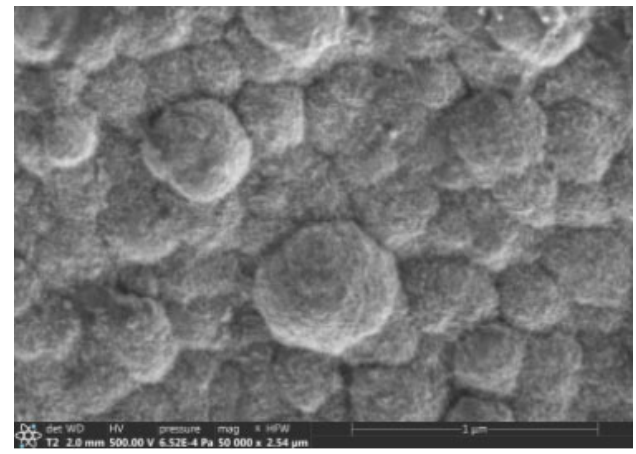

B

Рис. 3. Электронные микроизображения образцов сорбента $\mathrm{MnO}_{2}$-ТАЦ, полученных при различном времени экспозиции в растворе $\mathrm{KMnO}_{4}: 1$ час (а), 1 сутки (б, в)

Fig. 3. Electronic microimages of $\mathrm{MnO}_{2}$-CTA sorbent samples obtained for different exposure times in a $\mathrm{KMnO}_{4}$ solution: 1 hour (a). 1 dav (b. c)

с отдельных центров кристаллизации также подтверждается электронной микроскопией. На рис. 3 приведены электронные изображения образцов $\mathrm{MnO}_{2}-$ ТАЦ после 1 часа экспозиции и после 1 суток экспозиции в растворе перманганата калия. Видно, что после 1 часа экспозиции на поверхности ТАЦ присутствуют отдельные кристаллиты $\mathrm{MnO}_{2}$, тогда как уже после 1 суток экспозиции диоксид марганца образует практически сплошной слой, состоящий из глобулярных образований размером 0.2-0.6 мкм.
Очевидно, что различия в толщине слоя диоксида марганца, нанесенного на различные полимерные носители, в конечном счете приводят также и к различиям в текстуре поверхностей соответствующих модифицированных пленок. На рис. 4, 5 приведены оптические микрофотографии модифицированных пленок. По результатам оптической микроскопии образцов было установлено, что фаза диоксида марганца на поверхности сорбентов $\mathrm{MnO}_{2}$-ПЭ, $\mathrm{MnO}_{2}$-ПЭТФ,

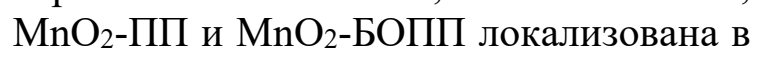




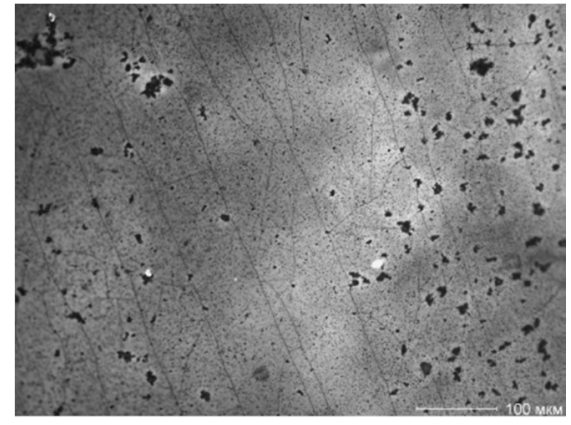

a

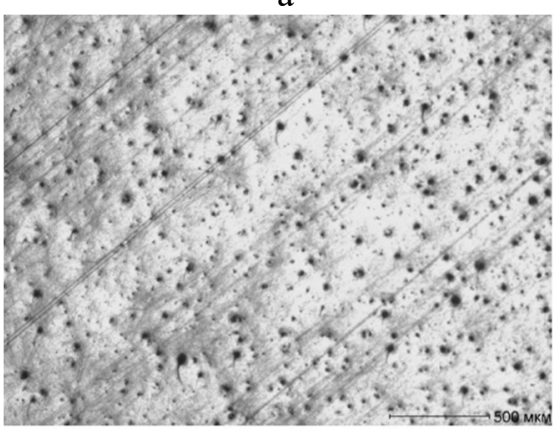

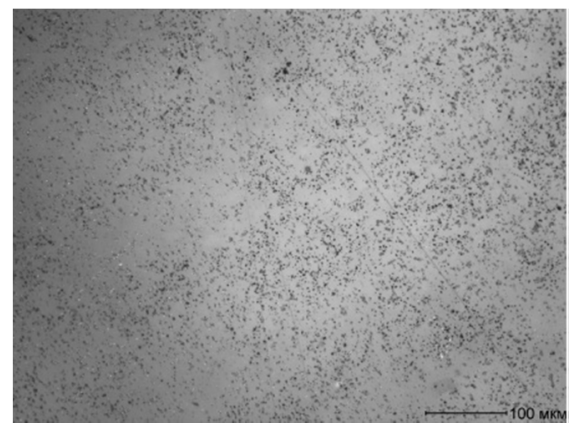

6

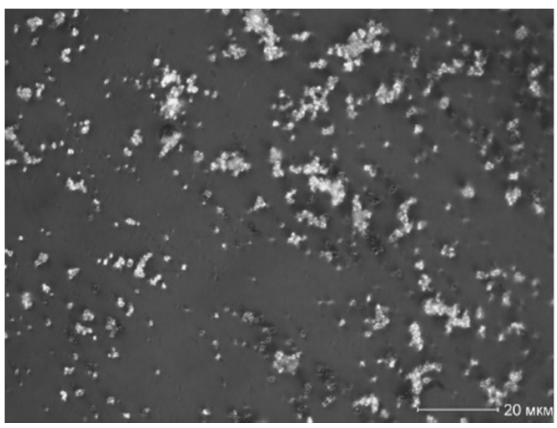

$\Gamma$

Рис. 4. Оптические микрофотографии образцов модифицированных сорбентов $\mathrm{MnO}_{2}$-ПЭ (a), $\mathrm{MnO}_{2}$-ПЭТФ, (б) $\mathrm{MnO}_{2}$-ПП, (в) $\mathrm{MnO}_{2}$-БОПП (г), синтезированных при времени экспозиции в растворе $\mathrm{KMnO}_{4} 163$ часа

Fig. 4. Optical micrographs of samples of modified $\mathrm{MnO}_{2}-\mathrm{PE}$ sorbent samples (a), $\mathrm{MnO}_{2}$-PET, (b) $\mathrm{MnO}_{2}-\mathrm{PP}$, (c) $\mathrm{MnO}_{2}-\mathrm{BOPF}$ (d) synthesized for exposure time of $163 \mathrm{~h}$ in $\mathrm{KMnO}_{4}$ solution

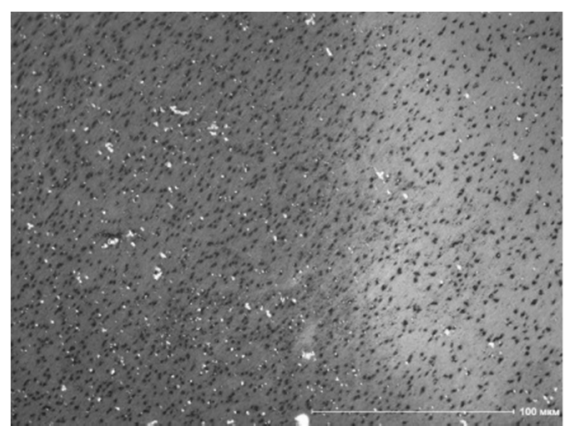

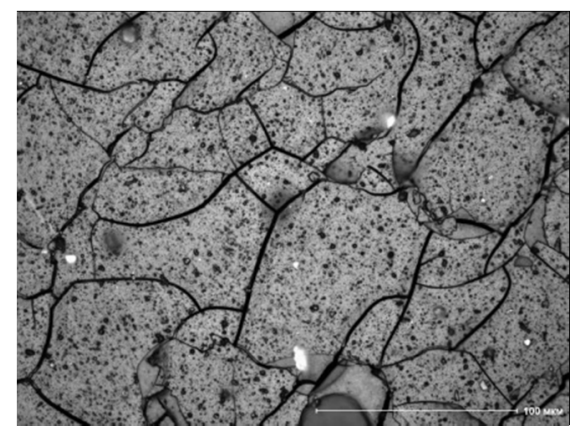

6

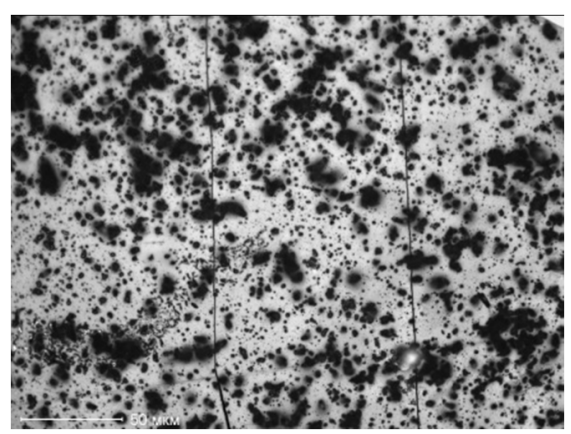

B

Рис. 5. Оптические микрофотографии (кратность увеличения $\times 500$ ) образцов сорбента $\mathrm{MnO}_{2}$-ТАЦ, полученных при различном времени экспозиции в растворе $\mathrm{KMnO}_{4}$ : 1 час (a), 1 сутки (б), 1 неделя (в)

Fig. 5. Optical micrographs (magnification $\times 500$ ) of $\mathrm{MnO}_{2}$-CTA sorbent samples obtained for different exposure times in a $\mathrm{KMnO}_{4}$ solution 1 hour (a), 1 day (b), 1 week (c) 
размера. Текстура поверхности сорбента $\mathrm{MnO}_{2}$-ТАЦ сильно зависела от удельного содержания диоксида марганца, обусловленного различным временем экспозиции в растворе $\mathrm{KMnO}_{4}$. Так при времени экспозиции 1 час фаза диоксида марганца так же, как и в случае других пленок образовывала отдельные кристаллиты. При большем времени (от 1 суток) фаза диоксида марганца образовывала сплошной слой на поверхности сорбента с сетью трещин размером 0.2-0.6 мкм. Дальнейший рост (более 3-4 суток) удельного содержания диоксида марганца, судя по всему, происходил за счет разрастания отдельных кристаллитов уже на поверхности сплошного слоя диоксида марганца, приводя к существенной неоднородности сорбционно-активной поверхности, а также к устойчивой деформации пленки.

Основной областью применения тонкослойных сорбентов на основе диоксида марганца на плоских носителях является анализ изотопов радия в водных пробах, при этом выбранная форма сорбентов позволяет совместить в одну стадию процесс сорбционного выделения радия и приготовление источника для альфаспектрометрии. При этом с точки зрения анализа наиболее важными параметрами являются степень сорбции радия и энергетическое разрешение получаемого альфа-спектра, которое численно выражается через ширину пика на половине высоты (ШППВ). Было определено влияние типа полимерного носителя на сорбцию радия-223. Приготовили две серии растворов, содержащих ${ }^{223} \mathrm{Ra}$, на основе дистиллированной воды (бессолевой раствор) и $0.5 \mathrm{M} \mathrm{NaCl} ; \mathrm{pH}=6-7, \mathrm{~V}=10 \mathrm{~cm}^{3}$. Образцы сорбентов $\left(4 \mathrm{~cm}^{2}\right)$ приводили в контакт с растворами, время сорбции составляло 3 суток. В таблице 3 приведены значения степени сорбции радия и ШППВ для соответствующих альфа-пиков. На рис. 6 приведены альфа-спектры сорбентов после сорбции радия-223.

Результаты показали, что в целом все сорбенты обладают примерно сходными

Таблица 3. Параметры сорбции радия-223 тонкослойными сорбентами на основе диоксида марганца из бессолевого раствора и 0.5 моль/дм ${ }^{3} \mathrm{NaCl}, \mathrm{pH}=6-7$.

Table 3. Parameters of sorption of radium-223 by thin-layer sorbents based on manganese dioxide from a salt-free solution and $0.5 \mathrm{~mol} / 1 \mathrm{NaCl}, \mathrm{pH}=6-7$.

\begin{tabular}{|c|c|c|c|c|}
\hline \multirow{2}{*}{ Сорбент } & \multicolumn{2}{|c|}{ Бессолевой раствор } & \multicolumn{2}{c|}{0.5 моль/дм ${ }^{3} \mathrm{NaCl}$} \\
\cline { 2 - 5 } & $\mathrm{S}, \%$ & ШППВ, кэB & $\mathrm{S}, \%$ & ШППВ, кэВ \\
\hline $\mathrm{MnO}_{2}$-ТАЦ & 80.3 & 90.4 & 47.9 & 78.1 \\
\hline $\mathrm{MnO}_{2}$-ПП & 85.9 & 52.9 & 14.1 & 56.4 \\
\hline $\mathrm{MnO}_{2}$-ПЭТФ & 82.1 & 46.3 & 21.1 & 37.4 \\
\hline $\mathrm{MnO}_{2}$-ПЭ & 84.1 & 50.7 & 42.2 & 52.1 \\
\hline $\mathrm{MnO}_{2}$-БОПП & 89.6 & 55.1 & 23.2 & 48.2 \\
\hline
\end{tabular}
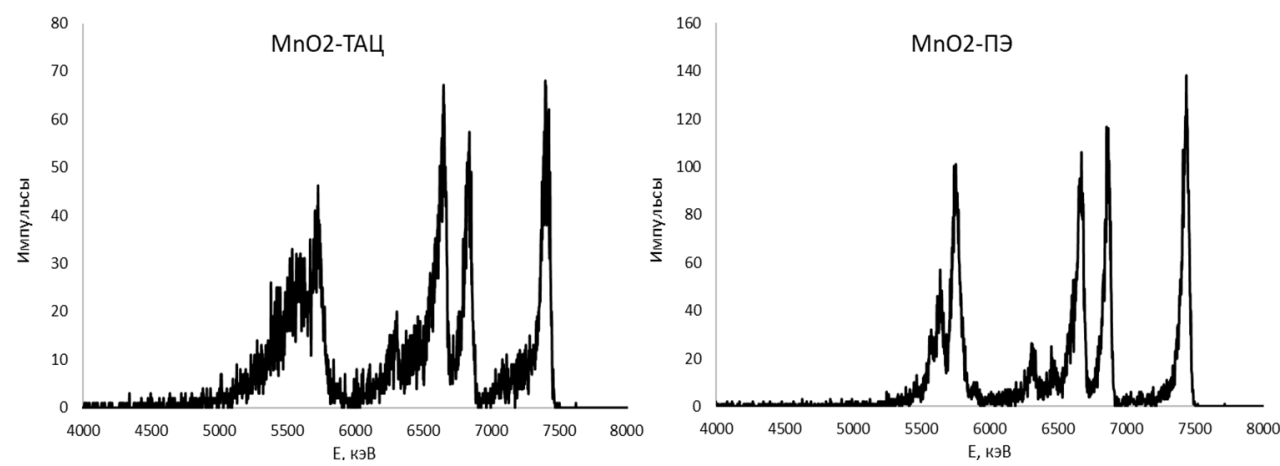

Рис. 6. Альфа-спектры тонкослойных сорбентов на основе диоксида марганца после сорбции ${ }^{223} \mathrm{Ra}$

Fig. 6. Alpha spectra of thin layer sorbents based on manganese dioxide after sorption of ${ }^{223} \mathrm{Ra}$ 
сорбционными характеристиками в бессолевых растворах: степень сорбции радия для всех сорбентов находилась в пределах 80-90\%. В то же время энергетическое разрешение для сорбентов на основе ПП, БОПП, ПЭ и ПЭТФ было также примерно одинаковым: ШППВ составило от 46 до 55 кэВ, что довольно близко к минимально возможной величине для данного спектрометра (35-40 кэВ), тогда как для сорбента $\mathrm{MnO}_{2}$-ТАЦ величина ШППВ была существенно больше - 90.4 кэВ, что можно объяснить диффузией радия вглубь сорбента за счет пористой текстуры носителя. Увеличение ШППВ до 90 кэВ привело к существенному ухудшению качества альфа-спектра, так что пики ${ }^{223} \mathrm{Ra}(5.716$ и 5.607 МэВ) оказались неразрешенными. Повышенная концентрация ионов натрия существенно подавляла сорбцию радия, что можно объяснить ионообменным механизмом сорбции радия. При этом интересно, что по степени сорбции сорбенты располагаются в ряд: $\mathrm{MnO}_{2}$-ТАЦ $>\mathrm{MnO}_{2}$-ПЭ $>\mathrm{MnO}_{2}$-БОПП $\approx$ $\mathrm{MnO}_{2}$-ПЭТФ > $\mathrm{MnO}_{2}$-ПП, что в целом коррелирует с количеством осажденной на данные носители фазы диоксида марганца. Таким образом, удельное содержание диоксида марганца на поверхности тонкослойных сорбентов оказалось несущественно в случае сорбции радия из слабосолевых растворов благодаря слабой конкуренции и достаточной сорбционной емкости для сорбции микроколичеств радионуклида, однако этот параметр становится критическим в случае повышения солесодержания из-за исчерпания сорбционной емкости конкурирующими ионами.

Таким образом, было установлено, что для аналитического применения наилучшим носителем оказался полиэтилен, для которого, с одной стороны, было характерно повышенное содержание диоксида марганца на поверхности, обеспечивающее повышенную емкость по отношению к радию, а, с другой стороны, качество альфа-спектров оставалось высоким за счет отсутствия диффузии радия вглубь сорбента.

\section{Заключение}

Синтезирован ряд плоских тонкослойных сорбентов, состоящих из диоксида марганца, нанесенного на поверхность различных носителей. В качестве носителей были использованы наиболее распространенные плоские материалы - полиэтилен (ПЭ), полипропилен (ПП), биаксиально-ориентированная полипропиленовая плёнка (БОПП), полиэтилентерефталат (ПЭТФ), триацетатцеллюлоза (ТАЦ). Показано, что по скорости осаждения диоксида марганца на поверхность носителя данные материалы располагаются в ряд: ТАЦ $>>$ ПЭ > БОПП > ПЭТФ $\approx$ ПП. Определено, что зависимости удельного содержания диоксида марганца на поверхности полимерных носителей хорошо аппроксимируются прямыми линиями $\left(\mathrm{R}^{2}=0.964-0.997\right)$; по результатам линейной обработки зависимостей были определены скорости осаждения диоксида марганца, составившие от $1.55 \pm 0.26$ мкг $/\left(\mathrm{cm}^{2} \cdot\right.$ сут $)$ для ПП до $166 \pm 11$ мкг/( $\mathrm{cm}^{2} \cdot$ сут $)$ для ТАЦ.

Показано, что высокая скорость осаждения диоксида марганца на поверхности ТАЦ по сравнению с другими полимерными носителями, наиболее вероятно, обусловлена макропористой текстурой поверхности ТАЦ. Также показано, что при удельном содержании диок-

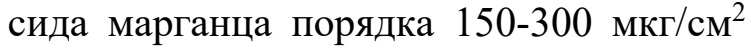
образуется сплошной равномерный сорбционно-активный слой.

Исследование сорбции радия на серии синтезированных сорбентов показало, что содержание диоксида марганца на их поверхности слабо влияет на сорбцию радия из бессолевого раствора (степени сорбции близки, 80-90\%), но является существенным фактором при сорбции из соленых сред. Для сорбента $\mathrm{MnO}_{2}$-ТАЦ после сорбции ${ }^{223} \mathrm{Ra}$ наблюдалось снижение качества альфа-спектра, обусловленное диффузией радия вглубь сорбента, что можно объяснить пористой текстурой 
триацетатцеллюлозы. Таким образом, полиэтилен был признан наилучшим носителем для синтеза тонкослойных сорбентов с целю анализа радия, поскольку, с одной стороны, для него было характерно повышенное содержание диоксида марганца на поверхности, обеспечивающее повышенную емкость по отношению к радию, а, с другой стороны, качество альфа-спектров оставалось высоким за счет беспористой текстуры носителя.

\section{Исследование выполнено при финансовой поддержке РФФИ} в рамках научного проекта № 20-03-00931

\section{Список литературы}

1. Ajith N., Swain K.K. // Separation Science and Technology. 2019. Vol. 55. Issue 9. pp. 1715-1723.

2. Shima J., Kumar M., Mukherjee S., Goswami R. // Journal of Environmental Management. 2019. Vol. 234. pp. 8-20.

3. Yang C., Zhong Y., Li L., Ren X. et al. // Journal of Radioanalytical and Nuclear Chemistry. 2018. Vol. 317. pp. 1399-1408.

4. Zuba I., Polkowska-Motrenko H. // Journal of Radioanalytical and Nuclear Chemistry. 2019. Vol. 322. pp. 969-974.

5. Yang C., Niu D., Zhong Y., Li L. et al. // Journal of Radioanalytical and Nuclear Chemistry. 2018. Vol. 315. pp. 533-542.

6. Ohnuki T., Kozai N. // Radiochimica Acta. 1995. Vol. 68. pp. 203-207.

7. Al Lafi A.G., Al Abdullah J., Amin Y., Alnama T., et al. // Journal of Radioanalytical and Nuclear Chemistry. 2019. Vol. 321. pp. 463-472.

8. Egorin A., Sokolnitskaya T., Azarova Y., Portnyagin A. et al. // Journal of Radioanalytical and Nuclear Chemistry. 2018. Vol. 317. pp. 243-251.

9. Eikenberg J., Bajo S., Beer H., Hitz J. et al. // Applied Radiation and Isotopes. 2004. Vol. 61 (2-3).pp. 101-106.

10. Moon D.S., Burnett W.C., Nour S., Horwitz P. et al. // Applied Radiation and Isotopes. 2003. Vol. 59. pp. 255-262

11. Kamran U., Heo Y.-J., Lee J. W., Park S.J. // Journal of Alloys and Compounds. 2019. Vol. 794. pp. 425-434
12. Wu S., Xie M., Zhang Q., Zhong L. et al. // Molecules. 2017. Vol. 22. P. 1117.

13. Shen Q., Wang Z., Yu Q., Cheng Y. et al. // Environmental Research. 2020. Vol. 183. pp. 109195.

14. Иванец А.И., Кацошвили Л.Л., Кривошапкин П.В., Прозорович В.Г. и др. // Радиохимия. 2017. Т. 59. № 3. С. 230-236.

15. White D.A., Labayru R. // Industrial \& Engineering Chemistry Research. 1991. Vol. 30. pp. 207-210.

16. Valsala T.P., Joseph A., Sonar N.L., Sonavane M.S. et al. // Journal of Nuclear Materials. 2010. Vol. 404. pp. 138-143.

17. Rao S.V.S., Mani A.G.S., Karua S., Cheralathan M. et al. // Journal of Radioanalytical and Nuclear Chemistry. 2016. Vol. 307. pp. 463-469.

18. Велешко А.Н., Кулюхин С.А., Велешко И.Е., Домантовский А.Г. и др. // Радиохимия. 2008. Т. 50. № 5. С. 439-445.

19. Yang Z., Chen J., Yang K., Zhang Q. et al. // Journal of Colloid and Interface Science. 2020. Vol. 570. pp. 182-196.

20. Karamanis D., Ioannides K.G., Stamoulis K.C. // Analytica Chimica Acta. 2006. Vol. 573-574. pp. 319-327.

21. Ra-NucFilm Disc (описание продукции). Режим доступа: https://www.triskem-international.com/scripts/files/59bd7516ebe5f0.12161 231/ft_nucfilmdiscs_en_151210.pdf (дата обращения: 15.01.2021)

22. Бетенеков Н.Д. // Радиохимия. 2018. Т. 60. № 5. С. 472-476. 


\title{
Study of the regularities of the deposition of thin sorption-active films of manganese dioxide on various polymeric carriers
}

\author{
(C) 2021 Semenishchev V.S., Oglezneva V.Yu., Titova S.M., \\ Malyshev A.S., Filinkova V.K. \\ Ural Federal University, Yekaterinburg
}

\begin{abstract}
Manganese dioxide $\left(\mathrm{MnO}_{2}\right)$ is used as a sorption material for the isolation of a wide range of substances from aqueous media. A number of composite materials containing $\mathrm{MnO}_{2}$ are known, while in the scientific literature there are no systematic data on the possibilities of obtaining flat thin-layer sorbents of manganese dioxide on other polymer carriers. In this study, a number of flat thin-layer sorbents, consisting of manganese dioxide deposited on the surface of various carriers, were synthesized. The most common flat materials were used as carriers - polyethylene (PE), polypropylene (PP), biaxially oriented polypropylene film (BOPF), polyethylene terephthalate (PET), cellulose triacetate (CTA). The films were kept in an acidic solution of potassium permanganate, washed, and the manganese content was determined. It was shown that according to the rate of deposition of manganese dioxide on the surface of the carrier, these materials are arranged in a row: $\mathrm{CTA}>>\mathrm{PE}>\mathrm{BOPF}>\mathrm{PET} \approx \mathrm{PP}$. It was found that the dependences of the specific content of manganese dioxide on the surface of polymer carriers were well approximated by straight lines $\left(R^{2}=0.964-0.997\right)$; the results of linear processing of the dependences were used to determine the deposition rates of manganese dioxide, ranging from $1.55 \pm 0.26 \mu \mathrm{g} /\left(\mathrm{cm}^{2} \cdot\right.$ day $)$ for PP up to $166 \pm 11 \mu \mathrm{g} /\left(\mathrm{cm}^{2}\right.$.day $)$ for CTA. It was shown that the high rate of deposition of manganese dioxide on the surface of the CTA in comparison with other polymer carriers was most likely due to the macroporous texture of the CTA surface. It was also shown that with a specific content of manganese dioxide of the order of $150-300 \mu \mathrm{g} / \mathrm{cm}^{2}$ achieved after 1-2 days of CTA treatment in a permanganate solution, a continuous uniform sorption-active layer was formed, and with a longer exposure time, an increase in the average layer thickness occurred due to the growth of individual crystallites already on the surface of a continuous layer of manganese dioxide, leading to a significant heterogeneity of the sorption-active surface, as well as to a stable deformation of the film. The sorption of ${ }^{223} \mathrm{Ra}$ was studied on a series of obtained sorbents. It was shown that the amount of manganese dioxide phase in the composition of thin-layer sorbents had practically no effect on the sorption of radium from a salt-free solution, but strongly influenced sorption from $0.5 \mathrm{M} \mathrm{NaCl}$. Also, for the $\mathrm{MnO}_{2}$-CTA sorbent the deterioration of the quality of the alpha spectrum due to the diffusion of radium deep into the sorbent was demonstrated.
\end{abstract}

Keywords: thin layer sorbents, manganese dioxide, precipitation, radium

\section{References}

1. Ajith N., Swain K.K., Separation Science and Technology, 2019, Vol. 55, Issue 9, pp. 1715-1723.

2. Shima J., Kumar M., Mukherjee S., Goswami R., Journal of Environmental Management, 2019, Vol. 234, pp. 8-20.

3. Yang C., Zhong Y., Li L., Ren X. et al., Journal of Radioanalytical and Nuclear Chemistry, 2018, Vol. 317, pp.1399-1408.

4. Zuba I., Polkowska-Motrenko H., Journal of Radioanalytical and Nuclear Chemistry, 2019, Vol. 322, pp. 969-974.

5. Yang C., Niu D., Zhong Y., Li L. et al., Journal of Radioanalytical and Nuclear Chemistry, 2018, Vol. 315, pp. 533-542.

6. Ohnuki T., Kozai N., Radiochimica Acta, 1995, Vol. 68, pp. 203-207.
7. Al Lafi A.G., Al Abdullah J., Amin Y., Alnama T. et al., Journal of Radioanalytical and Nuclear Chemistry, 2019, Vol. 321, pp. 463-472.

8. Egorin A., Sokolnitskaya T., Azarova Y., Portnyagin A. et al., Journal of Radioanalytical and Nuclear Chemistry, 2018, Vol. 317, pp. 243-251.

9. Eikenberg J., Bajo S., Beer H., Hitz J. et al., Applied Radiation and Isotopes, 2004, Vol. 61 (2-3), pp. 101-106.

10. Moon D.S., Burnett W.C., Nour S., Horwitz P. et al., Applied Radiation and Isotopes, 2003, Vol. 59, pp. 255-262.

11. Kamran U., Heo Y.-J., Lee J. W., Park S.J., Journal of Alloys and Compounds, 2019, Vol. 794, pp. 425-434.

12. Wu S., Xie M., Zhang Q., Zhong L. et al., Molecules, 2017, Vol. 22, pp. 1117.

13. Shen Q., Wang Z., Yu Q., Cheng Y. et al., Environmental Research, 2020, Vol. 183, pp. 109195. 
14. Ivanets A.I., Katsoshvili L.L., Krivoshapkin P.V., Prozorovich V.G. et al., Radiochemistry, 2017, Vol. 59, pp. 264-271.

15. White D.A., Labayru R., Industrial \& Engineering Chemistry Research, 1991, Vol. 30, pp. 207-210.

16. Valsala T.P., Joseph A., Sonar N.L., Sonavane M.S., et al., Journal of Nuclear Materials, 2010, Vol. 404, pp. 138-143.

17. Rao S.V.S., Mani A.G.S., Karua S., Cheralathan M. et al., Journal of Radioanalytical and Nuclear Chemistry, 2016, Vol. 307, pp. 463-469.

18. Veleshko A.N., Kulyukhin S.A., Veleshko I.E., Domantovskii A.G. et al., Radiochemistry, 2008, Vol. 50, pp. 508-514.

Семенищев Владимир Сергеевич - доцент кафедры радиохимии и прикладной экологии, к.х.н., доцент, Уральский федеральный университет, Екатеринбург

Оглезнева Валерия Юрьевна - магистрант кафедры радиохимии и прикладной экологии, Уральский федеральный университет, Екатеринбург

Титова Светлана Михайловна - доцент кафедры редких металлов и наноматериалов, к.т.н., Уральский федеральный университет, Екатеринбург

Малышев Андрей Сергеевич - аспирант кафедры редких металлов и наноматериалов, Уральский федеральный университет, Екатеринбург

Филинкова Варвара Кирилловна - студент бакалавриата кафедры радиохимии и прикладной экологии, Уральский федеральный университет, Екатеринбург
19. Yang Z., Chen J., Yang K., Zhang Q. et al., Journal of Colloid and Interface Science, 2020, Vol. 570, pp. 182-196.

20. Karamanis D., Ioannides K.G., Stamoulis K.C., Analytica Chimica Acta, 2006, Vol. 573574, pp. 319-327.

21. Ra-NucFilm Disc (technical sheet). Available at: https://www.triskem-internation al.com/scripts/files/59bd7516ebe5f0.12161231/ ft_nucfilmdiscs_en_151210.pdf (Accessed: 15 January 2021).

22. Betenekov N.D., Radiochemistry, 2018. Vol. 60, Issue 5, pp. 552-557.

Semenishchev Vladimir S. - Ph.D (chemistry), associated professor, department of radiochemistry and applied ecology, Ural Federal University, Yekaterinburg, e-mail: vovius82@mail.ru

Oglezneva Valeriya Y. - master student, department of radiochemistry and applied ecology, Ural Federal University, Yekaterinburg, e-mail: hoomea@mail.ru

Titova Svetlana M. - Ph.D (techn.), associated professor, department of rare metals and nanomaterials, Ural Federal University, Yekaterinburg, e-mail: avotitms@mail.ru

Malyshev Andrey S. - Ph.D student, department of rare metals and nanomaterials, Ural Federal University, Yekaterinburg, e-mail: a.s.malyshev@urfu.ru

Filinkova Varvara K. - bachelor student, department of radiochemistry and applied ecology, Ural Federal University, Yekaterinburg, e-mail: sherlocklocked@yandex.ru 